Ila Maria Corrêa ${ }^{1}$

Rosa Yasuko Yamashita ${ }^{2}$

André Vinícius Favrim Franco ${ }^{3}$

Hamilton Humberto Ramos ${ }^{4}$
'Doutora em Engenharia Agrícola, Pesquisadora do Centro de Engenharia e Automação/Instituto Agronômico (CEA/IA).

${ }^{2}$ Mestre em Engenharia Agrônoma, Pesquisadora da Fundação Jorge Duprat Figueiredo de Segurança e Medicina do Trabalho.

${ }^{3}$ Técnico em Informática, bolsista da Fundação de Amparo à Pesquisa do Estado de São Paulo.

${ }^{4}$ Doutor em Engenharia Agrônoma, Pesquisador do CEA/IA.

\section{Verificação de requisitos de segurança de tratores agrícolas em alguns municípios do estado de São Paulo}

\section{Checking security requirements for tractors in some regions in the state of São Paulo}

\begin{abstract}
Resumo
Um levantamento de informações foi realizado com o objetivo de avaliar as condições de segurança de tratores agrícolas novos e usados em alguns municípios do estado de São Paulo. Foram avaliados 487 tratores em uso em 270 propriedades agrícolas do estado de São Paulo e 31 tratores novos disponíveis em revendas e em exposição em feiras agrícolas, sendo inspecionados alguns requisitos de segurança relativos a posto de operação, acesso, comandos, proteção de partes móveis, disponibilização de avisos contra riscos de acidentes e requisitos necessários para tráfego em rodovias, previstos em documentos normativos nacionais e/ou internacionais. Verificou-se que os tratores em uso no campo não favorecem a segurança e o conforto do operador, enquanto que os tratores novos mostram tendência de atendimento aos requisitos de segurança e conforto, principalmente aqueles relacionados ao posto de operação e à proteção de partes ativas.
\end{abstract}

Palavras-chave: segurança do operador, acidentes com tratores, segurança de máquinas.

\begin{abstract}
A survey was held in some regions in the state of São Paulo aiming at evaluating safety conditions in used and brand new tractors. 487 tractors in use in 270 farms in the state of São Paulo were analyzed together with 31 brand new ones displayed in shops and fairs. The following were checked: the driver's seat, its accessibility, position of controls, protection against the active parts of the engine, warning signs disposal and consonance to the national and international safety regulations for highways driving. The final result showed that while the used tractors offer no comfort or security to the driver, the brand new ones seem to fulfill the requirements, mainly those related to the driver's seat and the protection of the engine active parts.
\end{abstract}

Keywords: the driver's safety, tractor accidents, engine protection. 


\section{Introdução}

Estatísticas nacionais e internacionais sobre acidentes rurais têm mostrado expressivo número de acidentes com tratores agrícolas. De acordo com levantamento de Corrêa et al. (2003), nos registros do Instituto Nacional de Segurança Social, o índice de acidentes com envolvimento de máquinas agrícolas é relativamente baixo (14,1\%) se comparado aos acidentes com ferramentas manuais $(34,2 \%)$ da atividade canavieira. No entanto, outras citações evidenciam a participação do trator nos acidentes ocorridos no meio rural. Becker (1994) relata que 13 $(37,1 \%)$ dos 35 acidentes fatais na agricultura ocorridos na Flórida, EUA, em 1992, eram relacionados à máquina ou trator agrícola. Schlosser et al. (2002), ao estudarem as características dos acidentes na Região Central do Rio Grande do Sul, verificaram que 39\% dos entrevistados já haviam sofrido algum tipo de acidente com tratores agrícolas. Niosh (1996) menciona o envolvimento do trator em 53\% dos acidentes agrícolas fatais no estado de Iowa, EUA.

Grande parte desses acidentes poderia ser evitada se as máquinas e os equipamentos envolvidos no acidente fossem dotados de dispositivos de segurança, se equipamentos de proteção individual fossem utilizados e se regras de segurança fossem observadas

\section{Material e Método}

O levantamento de dados foi realizado no período de agosto de 2000 a dezembro de 2001 em 270 propriedades agrícolas distribuídas em regiões de expressiva importância econômica do estado de São Paulo: Araraquara, Assis, Avaré, Barretos, Bragança Paulista, Jaboticabal, Jaú, Franca, Limeira, Marília, Itapeva, Itapetininga, Ourinhos, São João da Boa Vista, São José do Rio Preto, Sorocaba, Ribeirão Preto e Orlândia, tomadas a partir do IEA (Instituto de Economia Agrícola) 2000. Junto aos Escritórios de Desenvolvimento Regional da Coordenadoria de Assistência Técnica Integral, órgão de extensão rural do Governo de São Paulo, que conhece e mantém registro das propriedades agrícolas em cada região, buscou-se a indicação (aleatória) de propriedades representativas de pequenos a grandes produtores, que faziam uso da mecanização.

Os itens ou dispositivos de segurança verificados na máquina foram tomados principalmente das normas ISO 4253 (1993) e ABNT NBR ISO 4254-1 (1999). Também durante a execução das tarefas. No projeto de máquinas, o princípio fundamental de segurança é o de que ela seja apta a realizar sua função sem oferecer riscos às pessoas. Para isso, devem ser eliminados ou reduzidos, dentro do possível, os riscos existentes, adotadas medidas de proteção e disponibilizadas informações aos usuários sobre os riscos remanescentes. Conforme consta em Souza (2001), medidas de proteção automática (ex.: uso do protetor do eixo cardan) são preferenciais em relação às que dependam da ação do operador (prestar mais atenção, não se aproximar do eixo em movimento).É importante, portanto, que se leve em conta normas e regulamentos técnicos, nacionais e/ou internacionais, que estabelecem medidas de segurança no projeto da máquina.

O objetivo deste trabalho foi o de avaliar as condições de segurança dos tratores agrícolas (novos e usados) comercializados em São Paulo, estado que absorve a maior parte $(23,5 \%)$ da produção de tratores agrícolas de rodas no país, seguido do estado do Paraná, com 17,5\%, segundo a ANFAVEA (2004). Apresenta-se a situação dos tratores quanto a posto de operação, acesso, comandos, assento, estrutura de proteção contra capotagem, proteção de partes ativas, disponibilização de avisos contra riscos de acidentes e a requisitos necessários para tráfego em rodovia.

foram considerados outros itens, não explícitos em normas técnicas, mas cuja presença foi considerada importante por se relacionarem ao grau de conforto e de segurança do operador. Neste caso, inclui-se o cinto de segurança e os requisitos para tráfego em rodovias. Estes últimos tomaram como referência o Código Brasileiro de Trânsito (Lei 9503, de 23/09/1997).

Na avaliação dos itens de segurança, foram adotados os critérios abaixo:

a) Posto de operação: na identificação do tipo de posto de operação, foi utilizada a seguinte classificação: "acavalado" e "plataforma”. O posto de operação foi considerado como sendo do tipo acavalado quando era formado por apoios ou estribos colocados lateralmente ao monobloco de trator. Neste caso, o monobloco está em desnível em relação aos apoios e localiza-se entre as pernas do operador. O tipo plataforma é aquele em que a superfície do posto de operação é totalmente horizontal, montada sobre o monobloco ou o chassi. Para verificação da superfície antiderrapante, foi considerada a 
presença de orifícios ou material emborrachado que evitassem o escorregamento do pé na superfície do posto de operação.

b) Acesso ao posto de operação: para que o operador sinta-se confortável e seguro, não só o posto de operação, mas também o acesso a ele deve apresentar características específicas. No acesso ao posto de operação, os pontos relacionados à segurança e ao conforto do operador são as dimensões, a configuração dos degraus e a presença de manípulos. Se o degrau for muito alto, estreito demais e se não houver apoio adequado para as mãos, isso certamente dificultará a subida no trator, favorecendo uma situação de insegurança. A norma ABNT NBR ISO 42541 (1999) estabelece que os acessos com mono ou multidegraus devem ter largura igual ou superior a $200 \mathrm{~mm}$, altura do primeiro degrau de no máximo $550 \mathrm{~mm}$ e apresentar batente vertical de ambos os lados. Com relação ao manípulo, foi considerado como presente, neste trabalho, quando pelo menos um manípulo era disponível. Nos degraus, a superfície foi considerada antiderrapante quando apresentava rugosidades, cobertura com material lixa ou quando era descontínua, isto é, com barras verticais espaçadas.

c) Comandos no posto de operação e assento do operador: foram verificados a presença de regulagem do volante de direção e $\mathrm{o}$ atendimento à norma ABNT NBR ISO 4254-1 (1999) no que se refere às características do acionamento/desligamento da tomada de potência - TDP (identificação em cor vermelha, não exigência de esforço auxiliar e facilidade de acesso). Com relação ao assento, foram verificados a existência de regulagens horizontal e vertical do assento, a inclinação do encosto e o apoio para os braços.

d) Outras características do posto de operação: também relacionados ao conforto do operador, foram verificados a presença de cabine ou toldo solar para proteção contra o sol ou intempéries, o isolamento térmico do motor (incorporação de anteparo na parte frontal do posto de operação que favorecesse a proteção das pernas do operador contra o calor do motor; tratores cabinados foram considerados automaticamente isolados do

\section{Resultados e Discussão}

Nas 270 propriedades agrícolas visitadas, foram avaliados 487 tratores agrícolas. Em revendas e em feiras agrícolas, 31 tratores novos foram avaliados. As propriedades classificadas em função do tamanho da área apresentaram a seguinte calor do motor) e o direcionamento dos gases de escape, que segundo a ABNT NBR ISO 4254-1 (1999) deve estar acima da cabine ou do toldo solar.

e) Estrutura de proteção contra capotagem (EPCC): são estruturas montadas sobre o trator com a finalidade de garantir um espaço seguro para o operador, evitando ou limitando os riscos que o condutor corre em caso de capotagem do trator durante a sua utilização normal. Verificou-se, ainda, a presença de selo de certificação da EPCC, sendo considerada certificada a estrutura que apresentasse adesivo mencionando o atendimento de norma específica. O selo de certificação poderia ser emitido pelo fabricante do trator (autocertificação) ou laboratório especializado (certificação de terceira parte).

f) Proteção das partes móveis: presença de dispositivos (grade, tampa, defletor) que reduzem a possibilidade de contato com o órgão sob avaliação (polia do motor, pás de ventilador, eixo da tomada de potência). Para especificação dos tipos de proteção da tomada de potência (TDP), foram considerados os definidos na ABNT NBR ISO 4254-1 (1999): caixa ou invólucro, quando todos os lados próximos à TDP eram protegidos, e escudo ou tampa, quando pelo menos um lado era protegido. Foi verificada também a presença de um invólucro adicional, normalmente constituído de uma capa rosqueável, que é recomendado para uso quando a TDP não estiver sendo usada.

g) Avisos de advertência: presença de avisos em forma de texto, figura e/ou símbolos que façam advertência sobre os riscos relativos ao tombamento do trator, ao giro da TDP, à partida do motor e ao acoplamento de implementos.

h) Requisitos para tráfego em rodovias: presença de faróis dianteiros, luzes de freio, luzes de advertência, luz de direção, luz de ré, buzina, cinto de segurança, espelho retrovisor em pelo menos um dos lados e condições dos pneus (classificados em bom, médio e ruim, de acordo com a presença de cortes e, principalmente, do nível de desgaste apresentado).

distribuição por classes: abaixo de 50 ha: $38,5 \%$; entre 51 e 100 ha: $12,2 \%$; entre 101 e 200 ha: 20,7\%; entre 201 e 500 ha: $17,4 \%$; entre 501 e 1000 ha: 7,8\%; acima de 1000 ha: 3,3\%. Nessas propriedades agrícolas, os principais produtos eram 
milho, pecuária/pastagem, cana-de-açúcar, citros, soja, café e feijão.

Os 487 tratores em uso nas propriedades visitadas apresentavam a seguinte distribuição por idade: menos de 10 anos: 33,7\%; de 11 a 20 anos: $37,6 \%$; acima de 20 anos:
$27,1 \%$ e sem identificação: $1,6 \%$. Os dados refletem bem o envelhecimento da frota brasileira (64,7\% apresentavam mais de dez anos de uso). Na Tabela 1 é apresentada a classificação dos tratores por marcas, sendo que as marcas mais antigas foram grupadas dentro das mais atuais.

Tabela 1 Distribuição dos tratores segundo a marca comercial

\begin{tabular}{|c|c|c|}
\hline Marca & Trator usado & Trator novo \\
\hline & \multicolumn{2}{|c|}{$\%$ de presença } \\
\hline MF/AGCO & 49,9 & 19,4 \\
\hline VALTRA & 25,3 & 16,1 \\
\hline $\mathrm{CNH}$ & 15,8 & 25,8 \\
\hline JOHN DEERE & 2,5 & 12,9 \\
\hline CBT & 2,7 & - \\
\hline AGRALE & 2,0 & 12,9 \\
\hline YANMAR & 1,8 & 12,9 \\
\hline OUTRAS & 0,8 & - \\
\hline
\end{tabular}

As tabelas 2 a 7 resumem as características dos dispositivos avaliados.

a) Posto de operação e seu acesso: nos tratores usados, a média da altura obtida para o primeiro degrau foi de $583 \mathrm{~mm}$ (desviopadrão: $93 \mathrm{~mm}$ ), enquanto que a largura média dos degraus foi de $278 \mathrm{~mm}$ (desvio padrão: 56 $\mathrm{mm}$ ). Nos tratores novos, a altura média do primeiro degrau foi $537 \mathrm{~mm}$ (desvio padrão: $82 \mathrm{~mm}$ ) e a largura média dos mesmos foi de $365 \mathrm{~mm}$ (desvio padrão: $75 \mathrm{~mm}$ ). Na tabela 2 estão sintetizadas as características verificadas no local de trabalho do operador. Por aí se vê que apenas 48,1\% e 48,4\% dos tratores em uso atendem ao padrão da ABNT NBR 4254-1 (1999) em relação à altura do primeiro degrau e à existência de batente vertical em ambos os lados do degrau, respectivamente. Ressalte-se também a predominância do posto de operação tipo "acavalado" (73,9\% nos tratores em uso). Esse tipo de posto, além de oferecer certa dificuldade de acesso ao local de operação, restringe a inclusão de dispositivos que melhorem o conforto. Nos tratores novos, todos os requisitos estão com bons índices de representação. Quanto ao manípulo ou corrimão, é bom o índice de presença; no entanto, vale destacar que alguns não estão posicionados de maneira facilmente acessíveis, enquanto que, em alguns tratores, nos quais não havia nenhum ponto de apoio específico para as mãos, era utilizado o volante de direção. A presença de superfície antiderrapante, com índices superiores a 89\%, não é um fator preocupante nem para os tratores usados, nem para os novos.

Tabela 2 Características do posto de operação e seu acesso

\begin{tabular}{|c|c|c|}
\hline \multirow[t]{2}{*}{ Item avaliado } & Trator usado & Trator novo \\
\hline & - & \\
\hline \multicolumn{3}{|l|}{ Tipo do posto de operação } \\
\hline - Plataforma & 26,1 & 64,5 \\
\hline - Acavalado & 73,9 & 35,5 \\
\hline -Superfície antiderrapante & 89,2 & 96,8 \\
\hline \multicolumn{3}{|l|}{ Acesso ao posto de operação } \\
\hline Existência de degrau & 66,1 & 83,9 \\
\hline Altura do $1^{\circ}$ degrau $=550 \mathrm{~mm}^{(1)}$ & 48,1 & 88,5 \\
\hline Largura do $1^{\text {o }}$ degrau $=200 \mathrm{~mm}{ }^{(1)}$ & 69,3 & 92,3 \\
\hline Superfície antiderrapante ${ }^{(1)}$ & 55,9 & 88,5 \\
\hline Batente vertical $^{(1)}$ & 48,4 & 73,1 \\
\hline Manípulo/corrimão & 72,9 & 96,2 \\
\hline
\end{tabular}

${ }^{(1)}$ Em relação ao total de tratores com degraus (322 tratores usados e 26 novos).

b) Comandos no posto de operação e do assento do operador: Verifica-se, pela Tabela
3 , que é muito pequena a proporção $(8,6 \%)$ dos tratores agrícolas usados que apresentam 
regulagem do volante de direção. Esta regulagem, que se refere à inclinação do eixo vertical do mesmo, quando presente, adiciona conforto ao operador, pois permite que ele o ajuste as suas características pessoais. Como parte dos requisitos para as fontes de potência, a norma ABNT NBR 4254-1 (1999) estabelece que cada fonte de potência deva ser montada com um dispositivo que permita ser desligado rapidamente. Deve ser projetado de modo que não dependa do esforço manual auxiliado para sua operação e que seja facilmente acessível na sua posição manual de operação. O controle deve ser em cor vermelha e deve contrastar com o fundo e outros controles.

Tabela 3 Características dos comandos do posto de operação e do assento

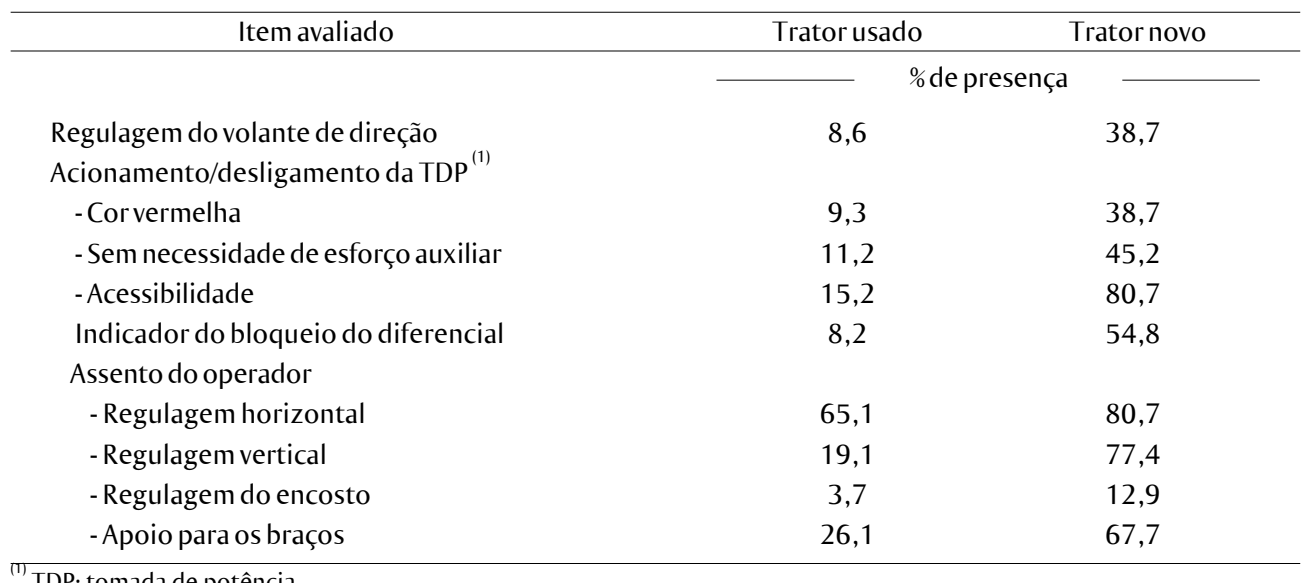

(I) TDP: tomada de potência.

Os dados apresentados na Tabela 3, com relação ao acionamento/ desligamento da tomada de potência, foram baseados no total de tratores que a apresentavam: 97,7\% e $100 \%$, respectivamente, para os tratores usados e novos.

Dos itens avaliados, apenas o referente à acessibilidade do comando nos tratores novos é o mais bem atendido, embora se verifique tendência favorável nos demais itens. Nos tratores em uso, a grande maioria não atende aos requisitos de norma, o que compromete a segurança do operador. Principalmente quando se faz necessário o desligamento da TDP em casos de emergência, é desejável que os comandos sejam acessados rapidamente sem esforço adicional, como virar ou abaixar o corpo para acessar o comando. A existência de um indicativo no painel que acuse quando o bloqueio do diferencial está acionado é importante para avisar do acionamento inadvertido e que possa causar acidente. Esse é um requisito normativo raramente presente nos tratores em uso (cerca de $8,2 \%$ ). Sua localização no posto de operação também é importante. Em um dos tratores analisados, a posição inadequada do dispositivo de acionamento do bloqueio fez com que o operador improvisasse um calço de madeira em cunha sob o pedal de acionamento para evitar que, sem querer, descansasse seu pé direito sobre o mesmo, como já acontecera várias vezes. Igualmente importante do ponto de vista do conforto do operador, são as características do assento mostradas na Tabela 3. Diversos autores citados por Debiasi (2002) concordam que um assento adequado reduz o trabalho estático muscular e favorece a postura corporal correta do operador, o que pode diminuir a ocorrência de doenças ocupacionais. As dimensões do assento (distância horizontal em relação ao volante e pedais; altura em relação à superfície de apoio; largura e comprimento do assento), juntamente com os ajustes (longitudinal e vertical) do assento, com a localização e com o ângulo do volante de direção, são alguns dos itens padronizados na norma ISO 4253 (1993). Com exceção dos ajustes longitudinal e vertical do assento, os demais itens verificados neste levantamento não são exigidos explicitamente em documentos normativos, mas contribuem para a redução da fadiga. Dentre os itens avaliados na Tabela 3, a regulagem da inclinação do encosto é o mais crítico tanto nos tratores novos quanto nos mais antigos. Chama a atenção, também, nos tratores em uso, a proporção de apenas $26,1 \%$ de tratores com apoio para os braços. Por outro lado, é favorável o aumento dessa proporção para nível próximo de 68\% nos tratores novos. Debiasi (2002) menciona que, em levantamento realizado na Itália, 41\% dos bancos eram equipados com apoio para os braços e, com relação às regulagens, $86 \%$ dos bancos não possuíam ajuste vertical, e a regulagem horizontal não estava presente ou não funcionava; além disso, $12,5 \%$ dos tratores 
avaliados possuíam um banco com estofamento severamente prejudicado ou totalmente retirado. Situação semelhante foi encontrada neste levantamento, pelo qual se verificou que alguns operadores buscavam minimizar o desconforto encontrado improvisando soluções (uso de espumas e lonas de plástico para forrar o assento ou encosto), nem sempre satisfatórias.

c) Outras características do posto de operação: pelos dados da Tabela 4, verifica-se que é bem expressiva a presença de proteção solar $(67,4 \%)$, mas a presença de cabine, dispositivo ideal para proteger o operador das intempéries, bem como do ruído proveniente do motor, é bastante baixa, pois apenas 2,5\% dos tratores em uso a apresentavam. Dos tratores avaliados em campo, 52,8\% não apresentavam nenhum tipo de EPCC. Tais estruturas deveriam ter resistência assegurada em testes oficiais (homologação) segundo normas técnicas, o que não é exigido no Brasil. Assim, a autocertificação, isto é, a declaração do fabricante atestando o atendimento da estrutura às normas técnicas é um instrumento legal, em favor do operador, sendo por isso verificado neste levantamento. Percebe-se pela Tabela 4 um aumento razoável na disponibilização de estruturas certificadas nos tratores atualmente comercializados, a exemplo do que ocorre nos países europeus, onde é prática comum a realização de ensaios por órgãos competentes. No campo, entretanto, é pequeno o número de tratores com estrutura certificada $(38,3 \%$ do total de tratores com algum tipo de EPCC).

Tabela 4 Outras características do posto de operação

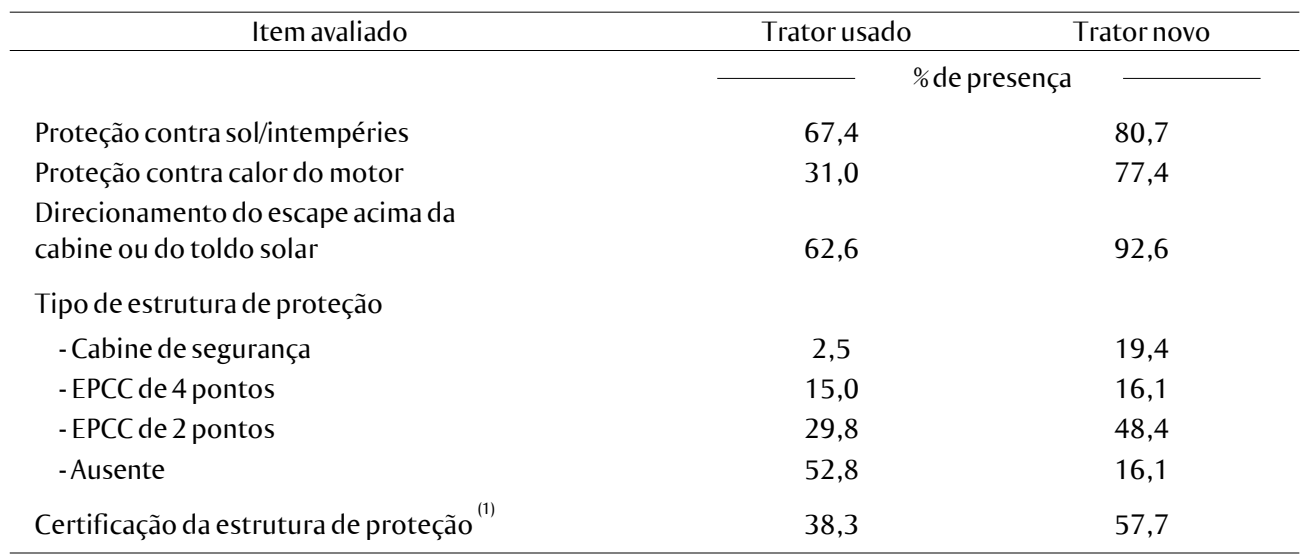

${ }^{(1)}$ Em relação aos tratores que apresentavam estrutura de proteção.

d) Proteção de partes móveis: Partindo do princípio de que "tratores e máquinas agrícolas e florestais devem ser projetados e construídos de tal modo que não causem perigo, quando utilizados adequadamente", a norma ABNT NBR 4254-1 (1999) define as partes consideradas perigosas, os tipos de proteções necessárias, os critérios de construção e os requisitos dimensionais para a prevenção de acidentes e a melhoria do grau de segurança pessoal dos operadores e de outros envolvidos no uso de tratores. A porcentagem da presença dos itens de proteção avaliados é apresentada na Tabela 5 . Verificou-se baixo índice de atendimento às normas técnicas, com 42,3\% e 17,0\%, respectivamente, para a proteção da polia do motor e da TDP. A proteção das pás do ventilador do sistema de arrefecimento do motor, apesar de presente na grande maioria dos casos, é parcial, pois se verificou que não impede, eventualmente, um contato manual com as pás. Da mesma forma ocorre com o invólucro adicional também previsto na norma ABNT NBR 4254-1 (1999). Segundo esta: "um invólucro adicional não giratório deve ser provido para uso quando a tampa ou invólucro não estiver na posição e quando a TDP não estiver em uso; este invólucro deve envolver completamente a TDP e ser fixado na carroceria do trator ou máquina”. $\mathrm{Na}$ prática, acontece que, mesmo sendo fornecido de fábrica, ele não é utilizado, o que é favorecido pelo fato do invólucro, na maioria absoluta dos casos, não ser fixado ao trator. Sendo removível, acaba sendo perdido ou deixado de lado. Pelo exposto, o nível de proteção das partes móveis dos tratores usados não é satisfatório, o que potencializa os riscos de acidentes no campo. Os tratores novos, entretanto, já incorporam de forma mais positiva todos esses dispositivos. 
Tabela 5 Características da proteção de partes móveis

\begin{tabular}{|c|c|c|}
\hline Item avaliado & Trator usa & Trator novo \\
\hline & 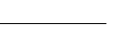 & \\
\hline \multicolumn{3}{|l|}{ Proteção de partes móveis } \\
\hline - Polia do motor & 42,3 & 87,1 \\
\hline - Pás do ventilador & 92,3 & 96,8 \\
\hline - Tomada de potência & 17,3 & 71,0 \\
\hline \multicolumn{3}{|l|}{ Tipo de proteção da TDP ${ }^{(1)}$} \\
\hline - Escudo ou tampa & 17,3 & 71,8 \\
\hline - Invólucro & 0,0 & 0,0 \\
\hline Invólucro adicional & 12,4 & ND* \\
\hline
\end{tabular}

${ }^{(1)}$ TDP: tomada de potência

*ND: Não determinado

e) Avisos de advertência: A norma ABNT NBR 4254-1 (1999) estabelece que "avisos de advertência duráveis devem ser fixados na máquina, naquelas partes que apresentam perigo para o operador, inclusive situações onde, o abaixamento inadvertido de partes do equipamento, possa causar perigo. Advertências específicas de segurança ou de perigo devem ser indicadas no aviso". Tais avisos devem ter também símbolos, diagramação e cores de acordo com a norma ISO 11684 (1995), o que não é visto normalmente. A Tabela 6 apresenta os resultados da avaliação da presença de avisos de advertência. Os baixos níveis de presença de avisos em todos os itens avaliados nos tratores usados indicam que este aspecto de prevenção não recebeu a importância que deveria ser dada pelos fabricantes, embora se perceba um certo nível de melhora nos tratores novos. Dentre os avisos com menor percentual de presença no levantamento efetuado, estão os relativos à tomada de potência $(9,0 \%$ nos usados; 41,9\% nos novos) e à orientação sobre acoplamento de implementos $(11,7 \%$ nos usados; 29,0\% nos novos). Contrapondo-se a outro requisito da norma ABNT NBR 4254-1 (1999), que estabelece que "o aviso de advertência deve ser ilustrado ou conter um texto em linguagem acessível ao usuário”, verificou-se em um dos tratores comercializados no Brasil adesivo de advertência em várias línguas, no qual o texto em português, se achava misturado a todos eles tornando confusa e de difícil percepção imediata a mensagem desejada.

Tabela 6 Presença de avisos de advertência

\begin{tabular}{|c|c|c|}
\hline Item avaliado & Trator usado & Trator novo \\
\hline & \multicolumn{2}{|c|}{ \%de presença } \\
\hline Risco de tombamento & 31,0 & 61,3 \\
\hline Risco de giro da TDP ${ }^{(1)}$ & 9,0 & 41,9 \\
\hline Partida do motor & 31,4 & 54,8 \\
\hline Orientação sobre acoplamento & 11,7 & 29,0 \\
\hline
\end{tabular}

(1) TDP: tomada de potência

f) Requisitos para tráfego em rodovias: Embora projetado para operar em zonas rurais, muitos agricultores servem-se do trator para deslocar-se de uma área para outra, utilizando-se não só de estradas de terras, como também de rodovias, sendo conhecidos muitos relatos de acidentes envolvendo tratores em rodovias. O limite máximo de velocidade, em torno de $40 \mathrm{~km} /$ $\mathrm{h}$, é um fator que, juntamente com a imprudência dos operadores, contribui para a ocorrência de acidentes. A incorporação de dispositivos para tráfego em rodovias, como faróis, espelhos, buzina, pisca alerta, sinalização de veículos lentos e outros, são, portanto, uma necessidade. Além disso, o trator agrícola é passível da aplicação do Código de Trânsito Brasileiro e, a rigor, deveria dispor dos mesmos equipamentos exigidos para automóveis, inclusive cinto de segurança e extintor de incêndio. O que se percebe, no entanto, pela Tabela 7 , é que os tratores mais antigos deixam muito a desejar sob este aspecto. Com exceção 
do farol dianteiro (82,7\% nos usados; $100 \%$ nos novos), os demais itens, apresentaram um baixo índice de presença, seja porque originalmente não são disponibilizados, seja porque não estavam funcionando. Em alguns casos, em que foi constatada a presença de espelho retrovisor e buzina, estes haviam sido instalados pelo operador.

Tabela 7 Características dos requisitos para tráfego em rodovias

\begin{tabular}{|c|c|c|}
\hline \multirow[t]{2}{*}{ Item avaliado } & Trator usado & \multirow{2}{*}{ Trator novo } \\
\hline & - & \\
\hline Farol dianteiro & 82,8 & 100,0 \\
\hline Luz de direção & 6,6 & 54,8 \\
\hline Luz de advertência & 6,8 & 64,5 \\
\hline Luz de freio & 19,1 & 77,4 \\
\hline Luz de ré & 1,0 & 9,7 \\
\hline Buzina & 5,9 & 64,5 \\
\hline Espelho retrovisor & 8,6 & 29,0 \\
\hline Cinto de segurança & 23,0 & 67,7 \\
\hline
\end{tabular}

Destaca-se também o estado de conservação dos pneus, sendo que quase metade (48\%) dos tratores em operação no campo apresentava condição de média a ruim devido à presença de cortes e desgaste da banda de rodagem. Nos tratores novos avaliados, notase que a presença de itens específicos para o tráfego em rodovia é bem maior (acima de $29,0 \%$ ), exceto para o item luz de ré, que tanto

\section{Conclusões}

A grande maioria dos tratores em uso em propriedades agrícolas de regiões economicamente importantes no estado de São Paulo não apresenta condições de segurança e conforto para o operador. No acesso ao posto de operação, onde há uma diversidade de tipos, as principais limitações dos degraus de acesso são a inexistência de batente vertical em ambos os lados e a altura do primeiro degrau, cuja média está acima do especificado por norma técnica. No posto de operação, são fatores de risco: o alto índice de posto tipo "acavalado", que não oferece segurança e conforto adequado; o alto índice de saída de escape abaixo do toldo solar ou da cabine; o baixo nível de proteção contra calor do motor. $\mathrm{O}$ índice de tratores sem qualquer tipo de estrutura de proteção contra capotamento é mais alto do que aqueles que possuem e, destes, muito poucos possuem certificação da estrutura. Dos requisitos para em tratores usados como em novos é muito baixa $(1,0 \%$ e $9,7 \%$, respectivamente).

Um levantamento realizado por Debiasi (2002) também atesta diversas limitações no que se refere às características de segurança nos tratores em uso na Região Central do Rio Grande do Sul, para os mesmos itens avaliados neste trabalho. tráfego em rodovias, o dispositivo mais freqüentemente disponível nos tratores analisados é o farol dianteiro.

Os demais são quase inexistentes. Também não são satisfatórios os índices de presença de avisos de advertência e de dispositivos de proteção de partes imóveis.

Nos tratores novos há tendência geral de atendimento aos requisitos de segurança e conforto do operador em quase todos os itens avaliados. São pontos favoráveis, na maioria dos casos: as características do posto de operação e seu acesso, a presença de cabine ou toldo solar, o direcionamento adequado do tubo de escape, as características do assento (regulagem e apoio), o nível de presença de estruturas de proteção contra capotamento, a proteção de partes móveis e os requisitos para tráfego em rodovias.

\section{Agradecimentos}

À Fundação de Amparo à Pesquisa do Estado de São Paulo pelo apoio financeiro ao projeto. 


\section{Referências Bibliográficas}

ASSOCIAÇÃO NACIONAL DOS FABRICANTES DE VEÍCULOS AUTOMOTORES ANFAVEA. Anuário Estatístico da Indústria Automobilística Brasileira 2004. São Paulo: Ponto e Letra Com. 158p.

ASSOCIAÇÃO BRASILEIRA DE NORMAS TÉCNICAS. NBR ISO 4254-1 - Tratores e máquinas agrícolas e florestais - Recursos técnicos para garantir a segurança - Parte 1: Geral. Rio de Janeiro: ABNT, 1999. 13 p.

BECKER, W. J. An analysis of agricultural accidents in Florida - 1992. University of Florida. Jan. 1994. 7p. Disponível em <http://www. cdc.gov/nasd/docs/d000001-d00100/ d000014/ d000014.pdf> Acesso em 22 março 2004.

CORREAA, I. M.; YAMSHITA, R. Y.; RAMOS, H. H.; FRANCO, A. V. F. Perfil dos acidentes rurais em agências do INSS de São Paulo no ano 2000. Revista Brasileira de Saúde Ocupacional. São Paulo: Fundacentro, v. 28, n. 107/108, p. 39-57, 2003.

DEBIASI, H. Diagnóstico dos acidentes de trabalho e das condições de segurança na operação de conjuntos tratorizados. 2002. Dissertação (Mestrado em Mecanização Agrícola) Universidade Federal de Santa Maria.

INSTITUTO DE ECONOMIA AGRÍCOLA IEA. Informações econômicas. São Paulo, v. 30, n.1, p. 85-96, jan. 2000.
INTERNATIONAL STANDARTIZATION FOR ORGANIZATION. ISO 4253 - Agricultural tractors - Operator's seating accommodation Dimensions. Genève: ISO, 1993. 4p.

ISO 11684 - Tractors, machinery for agriculture and forestry, powered lawn and garden equipment - Safety signs and hazard pictorials - General principles. Genève: ISO, 1995 (E), 52p.

NIOSH. Trac-safe - Facilitator's Manual. Cincinnati, Ohio: US Department of Health and Human Services, Public Health Service, CDC, 1996; DHHS (NIOSH) Publication no. 96-108. Disponível em <http://www.cdc.gov/niosh/ pdfs/tracsafe.pdf > Acesso em 08 maio 2003.

SCHLOSSER, J. F.; DEBIASI, H.; PARCIANELLO, G. Caracterização dos acidentes com tratores agrícolas. Ciência Rural. Santa Maria, v.32, n. 6, p. 977-981, 2002. Disponível em <http://www.scielo.br/ pdf/cr/v32n6/12742.pdf $>$.

SOUZA, S. P. de. Tombamento lateral de tratores agrícolas: avaliação do uso de um clinômetro para sua prevenção. 2001. Dissertação (Mestrado em Máquinas Agrícolas) Escola Superior de Agricultura Luiz de Queiroz. 